\title{
A framework for information technology-based management against COVID-19 in Iran
}

\author{
Afsoon Asadzadeh ${ }^{1,2}$, Zeinab Mohammadzadeh², Zahra Fathifar ${ }^{1,2}$, Soheila Jahangiri-Mirshekarlou ${ }^{1,2}$ and \\ Peyman Rezaei-Hachesu $2^{2^{*}}$ (D)
}

\begin{abstract}
Background: The COVID-19 pandemic has become a global concern. Iran is one of the countries affected most by the SARS-CoV-2 outbreak. As a result, the use of information technology (IT) has a variety of applications for pandemic management. The purpose of this study was to develop a conceptual framework for responding to the COVID-19 pandemic via IT management, based on extensive literature review and expert knowledge.
\end{abstract}

Methods: The conceptual framework is developed in three stages: (1) a literature review to gather practical experience with IT applications for managing the COVID-19 pandemic, (2) a study of Iranian documents and papers that present Iran's practical experience with COVID-19, and (3) developing a conceptual framework based on the previous steps and validating it through a Delphi approach in two rounds, and by 13 experts.

Results: The proposed conceptual framework demonstrates that during pandemics, 22 different types of technologies were used for various purposes, including virtual education, early warning, rapid screening and diagnosis of infected individuals, and data management. These objectives were classified into six categories, with the following applications highlighted: (1) Prevention (M-health, Internet search queries, telehealth, robotics, Internet of things (IoT), Artificial Intelligence (AI), big data, Virtual Reality (VR), social media); (2) Diagnosis (M-health, drones, telehealth, IoT, Robotics, Al, Decision Support System (DSS), Electronic Health Record (EHR)); (3) Treatment (Telehealth, M-health, Al, Robotic, VR, loT); (4) Follow-up (Telehealth, M-health, VR), (5) Management \& planning (Geographic information system, M-health, loT, blockchain), and (6) Protection (loT, Al, Robotic and automatic vehicles, Augmented Reality (AR)). In Iran, the use of IT for prevention has been emphasized through M-health, internet search queries, social media, video conferencing, management and planning objectives using databases, health information systems, dashboards, surveillance systems, and vaccine coverage.

Conclusions: IT capabilities were critical during the COVID-19 outbreak. Practical experience demonstrates that various aspects of information technologies were overlooked. To combat this pandemic, the government and decisionmakers of this country should consider strategic planning that incorporates successful experiences against COVID-19 and the most advanced IT capabilities.

Keywords: Information technology, COVID-19, Infectious disease, Outbreak, Epidemic

*Correspondence: rezaeip@tbzmed.ac.ir

${ }^{2}$ Health Information Technology Department, School of Management and Medical Informatics, Tabriz University of Medical Sciences, Daneshgah St, 5165665811 Tabriz, Iran

Full list of author information is available at the end of the article

\section{Background}

Recently, coronavirus 2019 (COVID-19) emerged as a global infection disease caused by severe acute respiratory syndrome coronavirus 2 (SARS-CoV-2) in Wuhan, 
China, on December 31, 2019, has since spread worldwide [1]. The primary concern in the COVID-19 outbreak is the pathogen's ability to infect humans and cause a variety of clinical symptoms and severity [2]. Patients with COVID-19 frequently experience fever, dry cough, muscle ache, fatigue, shortness of breath, weakness, chest tightness, nasal congestion, and sore throat [3]. This pandemic has significantly impacted numerous facets of human life, including public health, well-being, businesses, education, and entertainment $[1,4]$.

Presently, SARS-CoV-2 has been detected in 222 countries [5], with Iran being one of the countries most affected by the virus [6]. The first COVID-19 cases in Iran were reported on February 19, 2020, and by March 5, 2020, all 31 provinces of Iran had been infected [7]. By July 5, 2021, the number of confirmed patients in this country was $3,270,843$, with 84,949 deaths and 2,940,874 recoveries reported [5]. Following a sharp increase in COVID-19 cases, governments worldwide are implementing plans, including restriction and management strategies, to contain and prevent the current pandemic's spread [8]. IT is viewed as a critical component of emergency management for the COVID-19 pandemic in various dimensions, including mitigation, preparedness, prevention, diagnosis, screening, treatment, and recovery $[9,10]$ IT is defined as the use of computers and other information technology to acquire, organize, store, retrieve, and disseminate information [11]. IT can significantly reduce the costs associated with coordination, communication, and information processing [12].

During this pandemic, several studies have been conducted to demonstrate IT applications' effectiveness against COVID-19 [9, 13-15]. There is a need to conduct studies to illustrate each country's practical experience with IT-based COVID-19 management to determine which digital solutions should be emphasized or ignored
[9]. It should be noted that presenting the conceptual framework for managing current pandemics based on IT potentials will help inform government, policymakers, software designers, informatics, and health information technology experts on how to use and plan IT-based solutions for the COVID-19 epidemic's emergency management. As a result, the primary goal of the current study was to develop a framework for managing pandemics based on IT's practical experience in Iran. Then, based on extensive literature and expert knowledge, a comprehensive framework for managing the COVID-19 pandemic is proposed.

\section{Methods}

There are three phases to the current study's methodology (Fig. 1). The papers identified from the information sources (see Section Databases and search strategy) were screened according to inclusion and exclusion criteria (see Section Inclusion and Exclusion criteria) by three authors (AA, PRH, and ZM). They reviewed the full text of included papers demonstrating various IT solutions used during the COVID-19 pandemic. The information of forty articles were extracted and shown in Table 2. Each gathered IT solution was searched through Iranian databases and official websites during the second phase to determine which technologies were used. The third phase proposed an initial framework based on the findings of the first and second phases, which were then sent to experts for validation and completion. The following figure depicts an overview of the three phases.

\section{Phase 1. Literature review \\ Databases and search strategy}

A literature review was conducted to identify studies that documented the use of IT in the management of the COVID-19 outbreak. We selected appropriate keywords

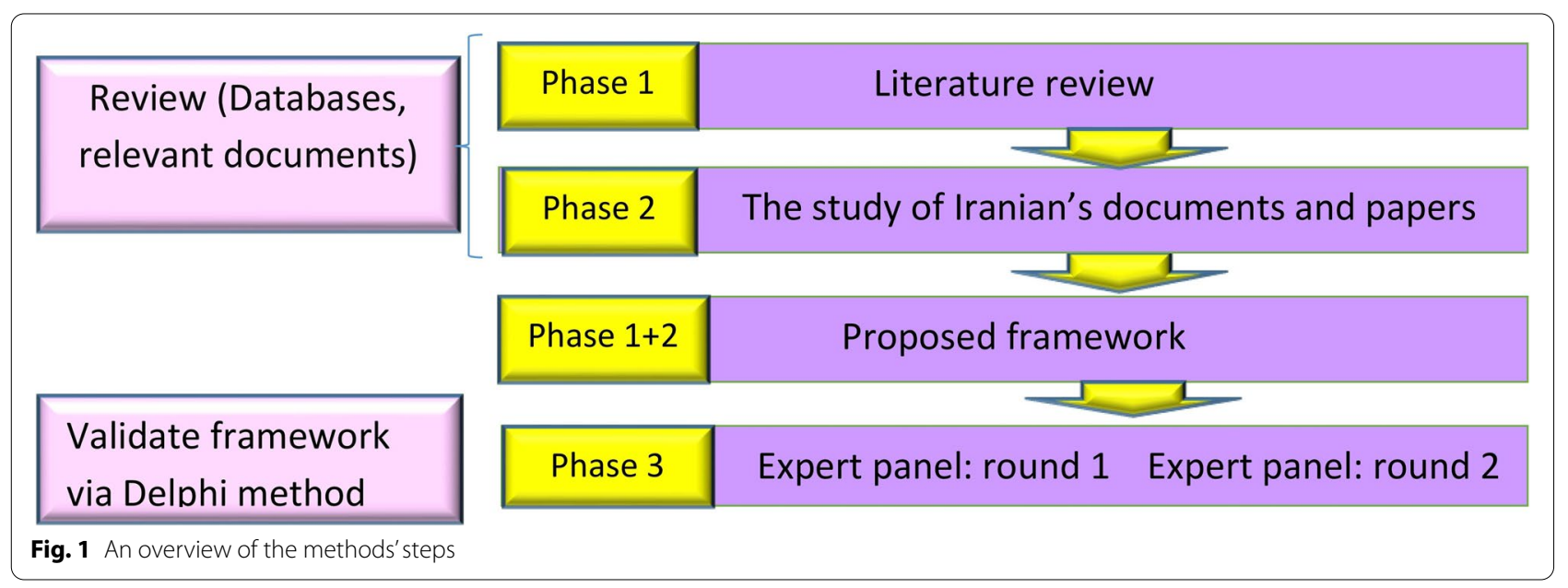


based on related articles and the advice of experts in health information technology, health information management, and medical informatics (Table 1). MEDLINE (PubMed), Embase, IEEE, Scopus, Web of Science, Google Scholar, and the Google search engine were used to search keywords between December 2019 and April 2021. The current study's search strategy is summarized in Table 1.

\section{Inclusion and exclusion criteria}

This study included review articles on IT solutions, peerreviewed studies, and English language papers. Letters to the Editor, opinions, protocols, and studies unrelated to the topic were excluded.

\section{Data extraction}

The identified publications were added to an EndNote X8 library, and duplicates were eliminated. Three authors screened the articles in three stages: (1) Title, (2) Abstract and (3) Full text. Disagreements with the fourth and fifth authors were resolved via an online meeting. The following data were extracted for the COVID-19 pandemic: authors, IT types, and applications of the technologies included. Finally, the extracted applications were used to classify the results into sub-themes.

\section{Phase 2. IT used for COVID-19 in Iran}

Related papers or documents for IT applications in Iran were extracted from (1) phase 1 (see Section Phase 1. Literature review), (2) official Iranian websites (i.e., the

Table 1 The search strategy

\begin{tabular}{|c|c|}
\hline Search & Details \\
\hline$\# 1$ & $\begin{array}{l}\text { ["covid 19"[Title/Abstract] OR"2019 ncov"[Title/ } \\
\text { Abstract] OR"2019 cov"[Title/Abstract] OR } \\
\text { "coronavirus"[Title/Abstract] OR"novel } \\
\text { coronavirus"[Title/Abstract] OR "coronavirus } \\
2019 \text { "[Title/Abstract] OR"sars cov 2"[Title/ } \\
\text { Abstract] OR "SARS-CoV-2"OR"coronavirus disease } \\
\text { 2019"[Title/Abstract] OR "Severe acute respira- } \\
\text { tory syndrome coronavirus 2"[Title/Abstract] OR } \\
\text { "COVID-19"[Mesh]]. }\end{array}$ \\
\hline \#2 & $\begin{array}{l}\text { "Information Technology"[Mesh] AND "informa- } \\
\text { tion technology" [Title/Abstract] OR "IT" [Title/ } \\
\text { Abstract] OR"Informatics" [Title/Abstract] OR } \\
\text { "informatics" [Title/Abstract] OR "computer tech- } \\
\text { nology" [Title/Abstract] OR "electronic technology" } \\
\text { [Title/Abstract] OR"Information and Communica- } \\
\text { tion Technology" [Title/Abstract] OR "ICT" [Title/ } \\
\text { Abstract] OR "computerized information" [Title/ } \\
\text { Abstract] OR "Information system" [Title/Abstract] } \\
\text { OR"Infotech" [Title/Abstract] OR "data processing" } \\
\text { [Title/Abstract] }\end{array}$ \\
\hline \multirow[t]{2}{*}{ \#3 } & $\# 1 \mathrm{AND} \# 2$ \\
\hline & Limits: English language \\
\hline
\end{tabular}

Ministry of Health and Medical Education, academic, and "The National Headquarters for Coronavirus Control"), and (3) Iranian databases including SID, IRAN MEDEX, and Islamic World Science Citation Center (ISC). Published documents between December 2019 and April 2021 were reviewed by all five authors.Finally, a conceptual framework for IT-based management of the COVID-19 was provided based on this country's practical experiences.

\section{Phase 3. Proposed conceptual framework and validation}

Based on the results from the first and second phases, a comprehensive conceptual framework was developed. It was distributed to experts with Ph.D. degrees and relevant experience, including health information technology/health information management $(N=11)$ and information technology (IT) experts $(N=3)$, who were asked to validate and apply their knowledge within the proposed framework for completion during 20 days. The framework was modified in response to expert recommendations, and the framework's vulnerabilities were addressed. Finally, they were contacted to finalize the conceptual framework.

\section{Results}

\section{Phase 1: Literature review for IT-based management} of COVID-19

Phase 1 included forty review articles. Based on the results, the major components of IT used for COVID-19 have been classified and summarized in Table 2 .

As a result of our findings, the IT objectives for COVID-19 can be classified into six categories: (1) prevention and control (i.e., actions taken during the pandemic to prevent further outbreaks), (2) diagnosis and detection, (3) treatment, (4) follow-up, (5) protection strategies (i.e., the safety of health care providers and the general public during the pandemic), and (6) management and planning strategies. Table 2 details these classifications and their associated cases.

Phase 2. The examination of Iranian documents and papers Iran's approach to managing COVID-19 through IT capabilities are depicted in Fig. 2. The information was completed and validated with the assistance of experts.

In Iran, specific IT applications have been used to accomplish four primary goals: (a) Prevention, (b) Diagnosis, (c) Treatment and (d) Management and planning (see Fig. 2 for details).

\section{a) Prevention}

The "Mask" application is a mobile application developed in Iran to educate the public about COVID-19. This app displays the most recent news regarding COVID-19 


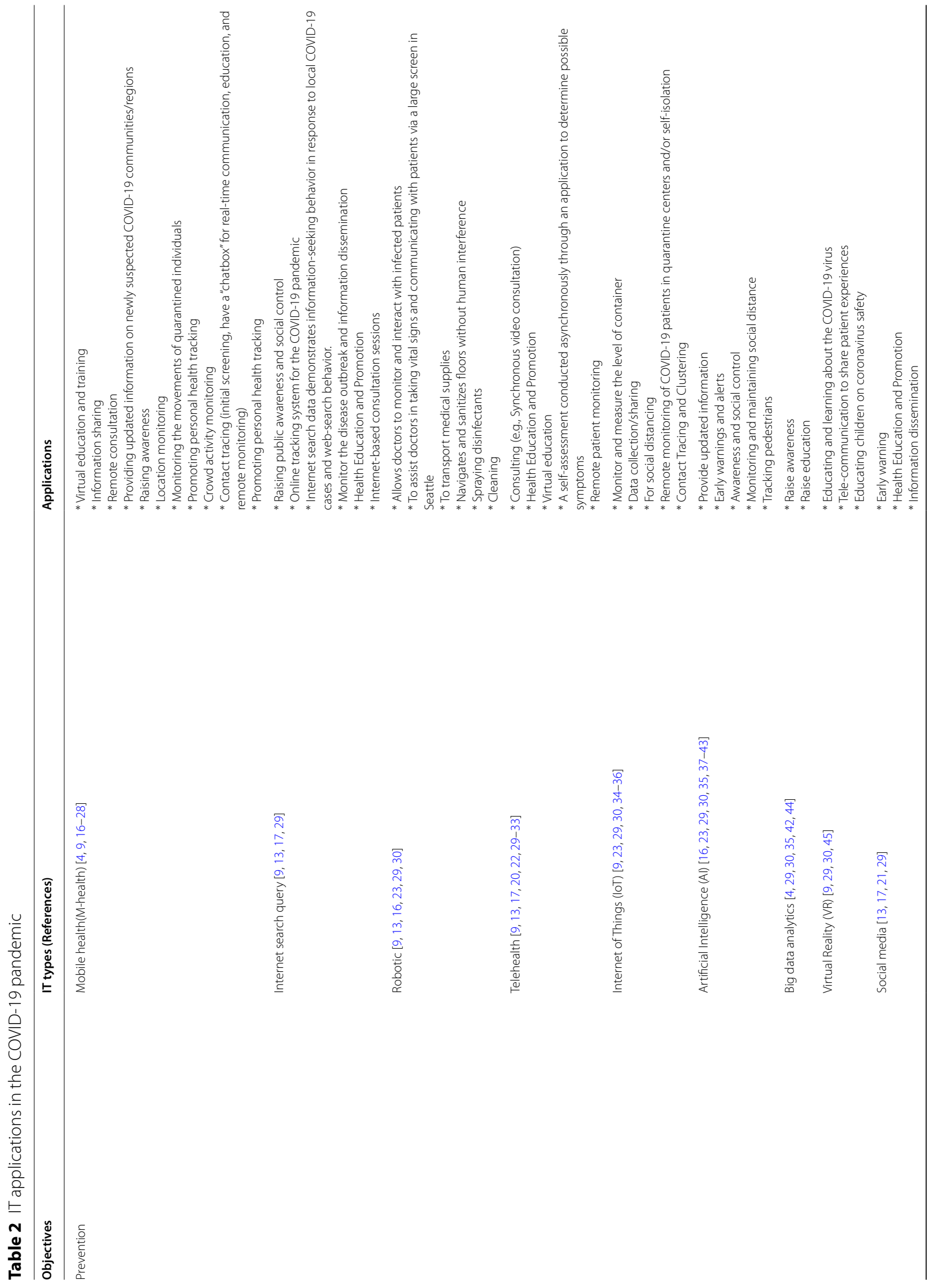




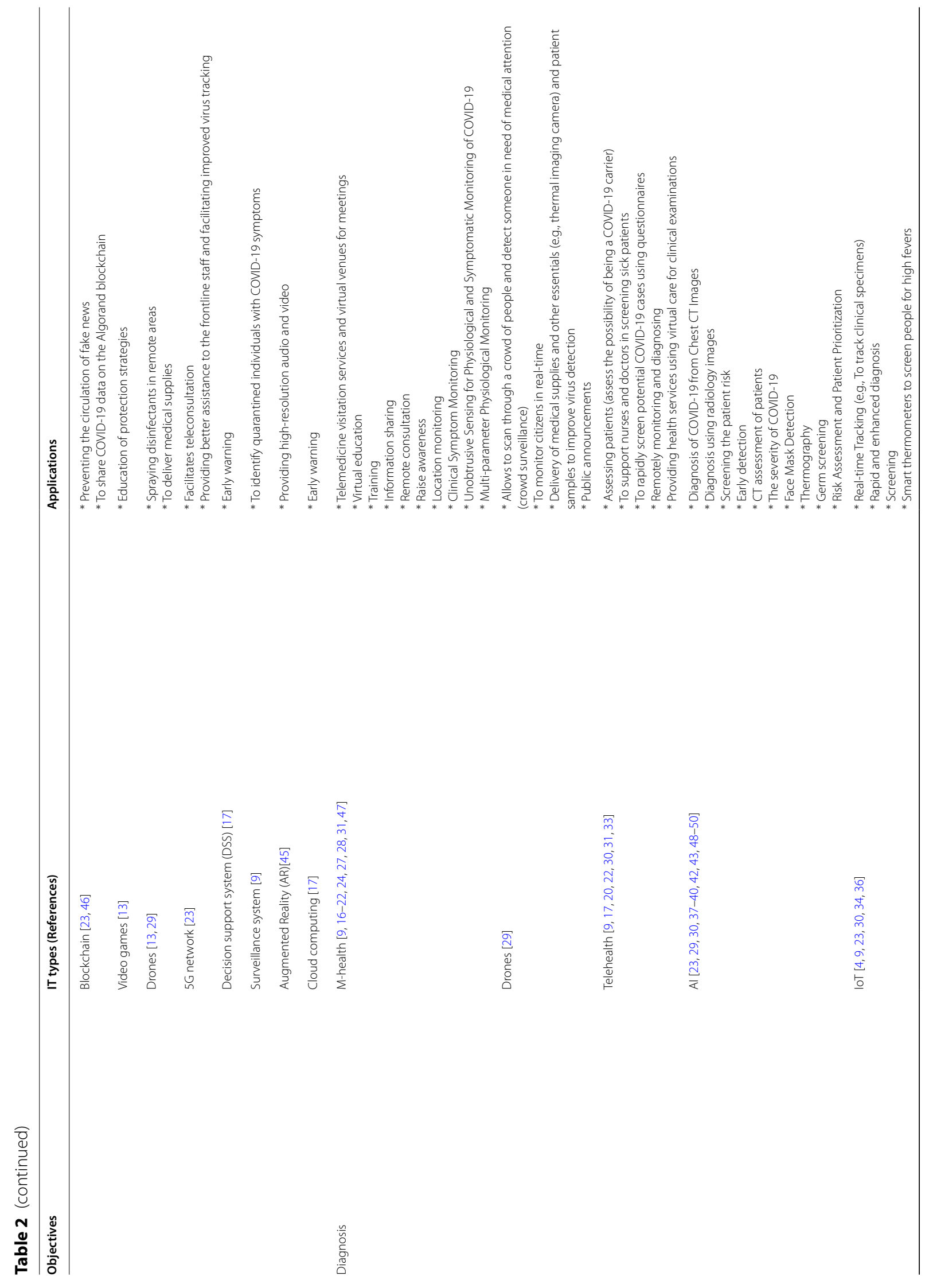




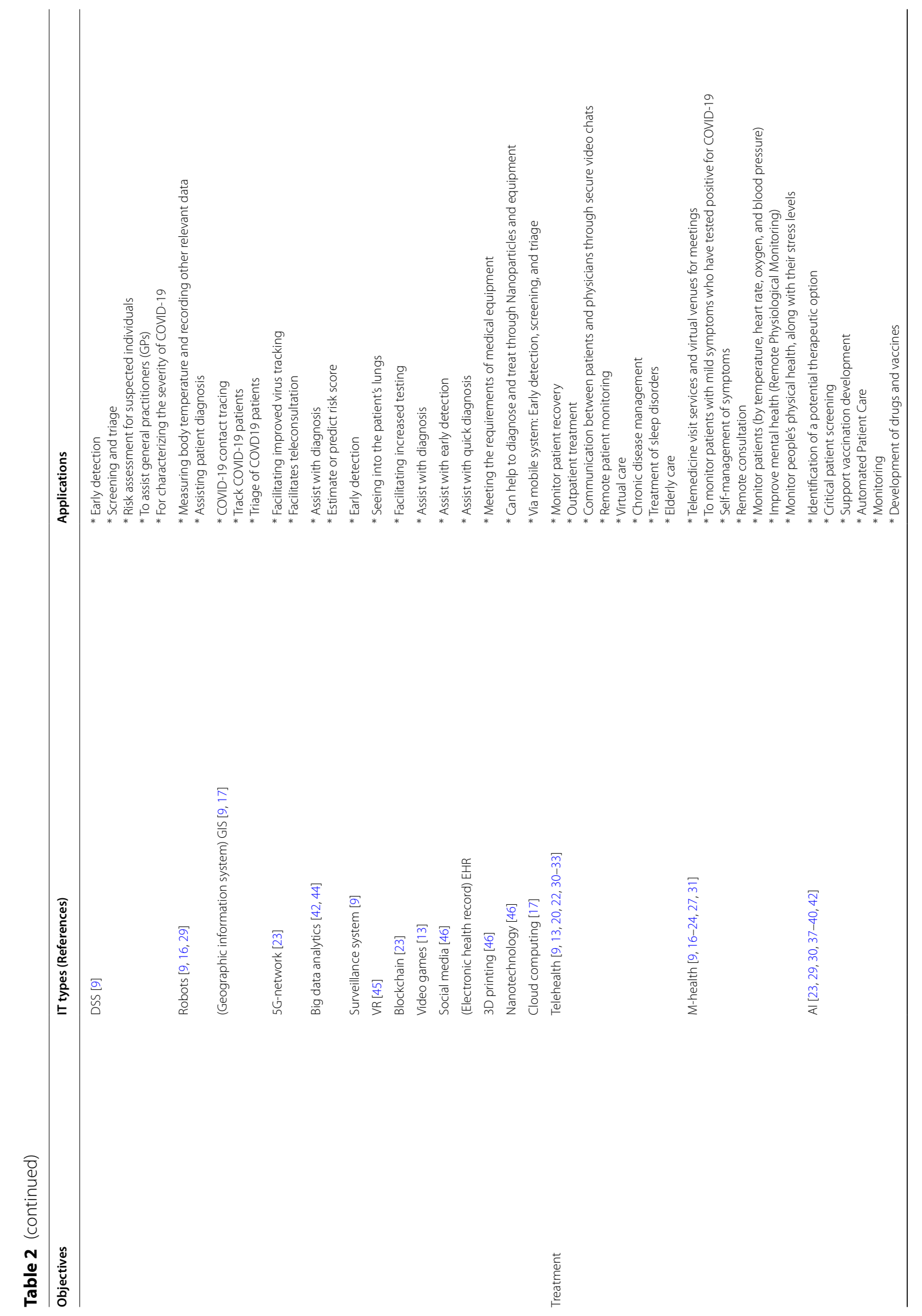




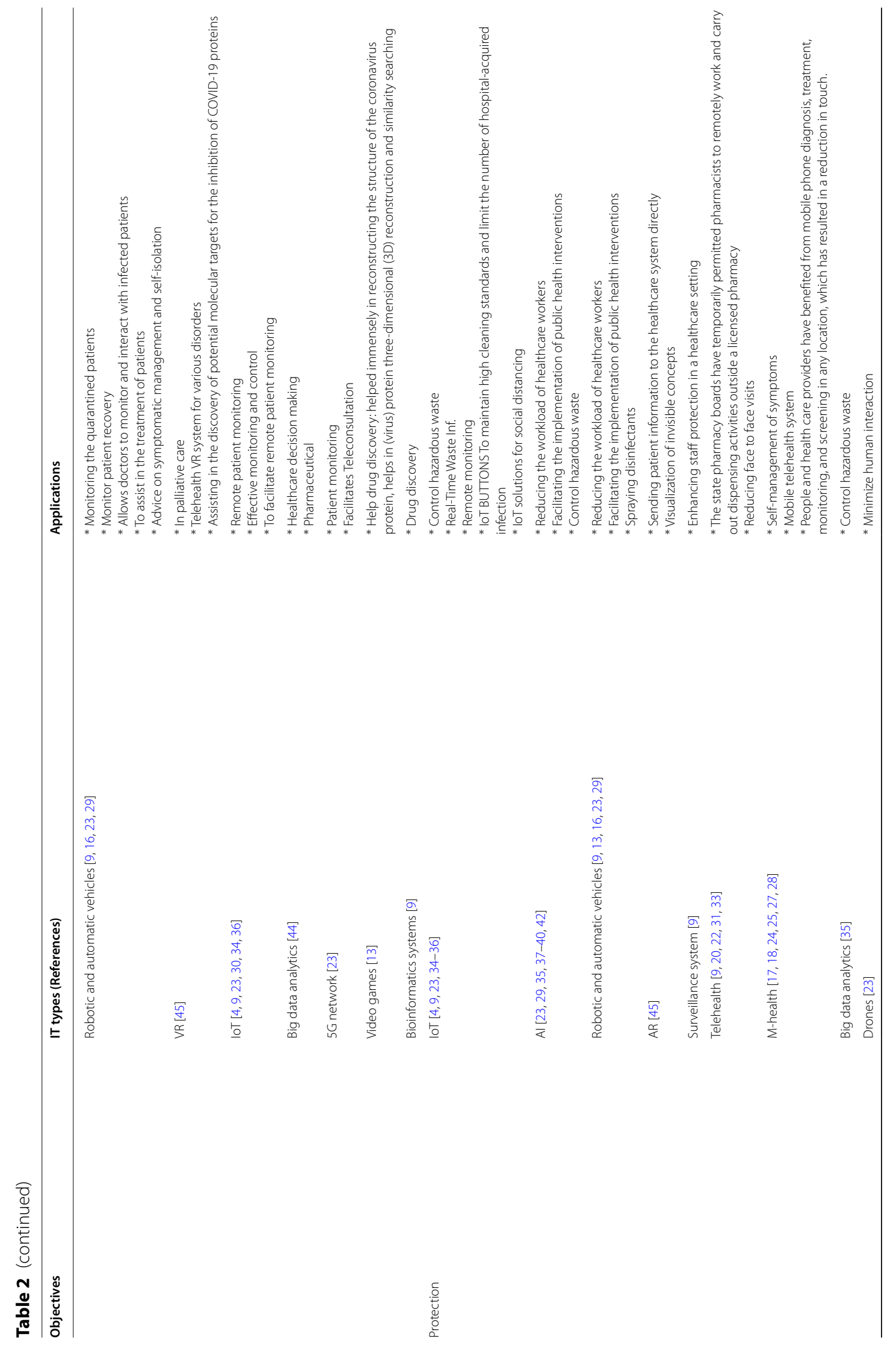


Asadzadeh et al. BMC Public Health $\quad$ (2022) 22:402

Page 8 of 15

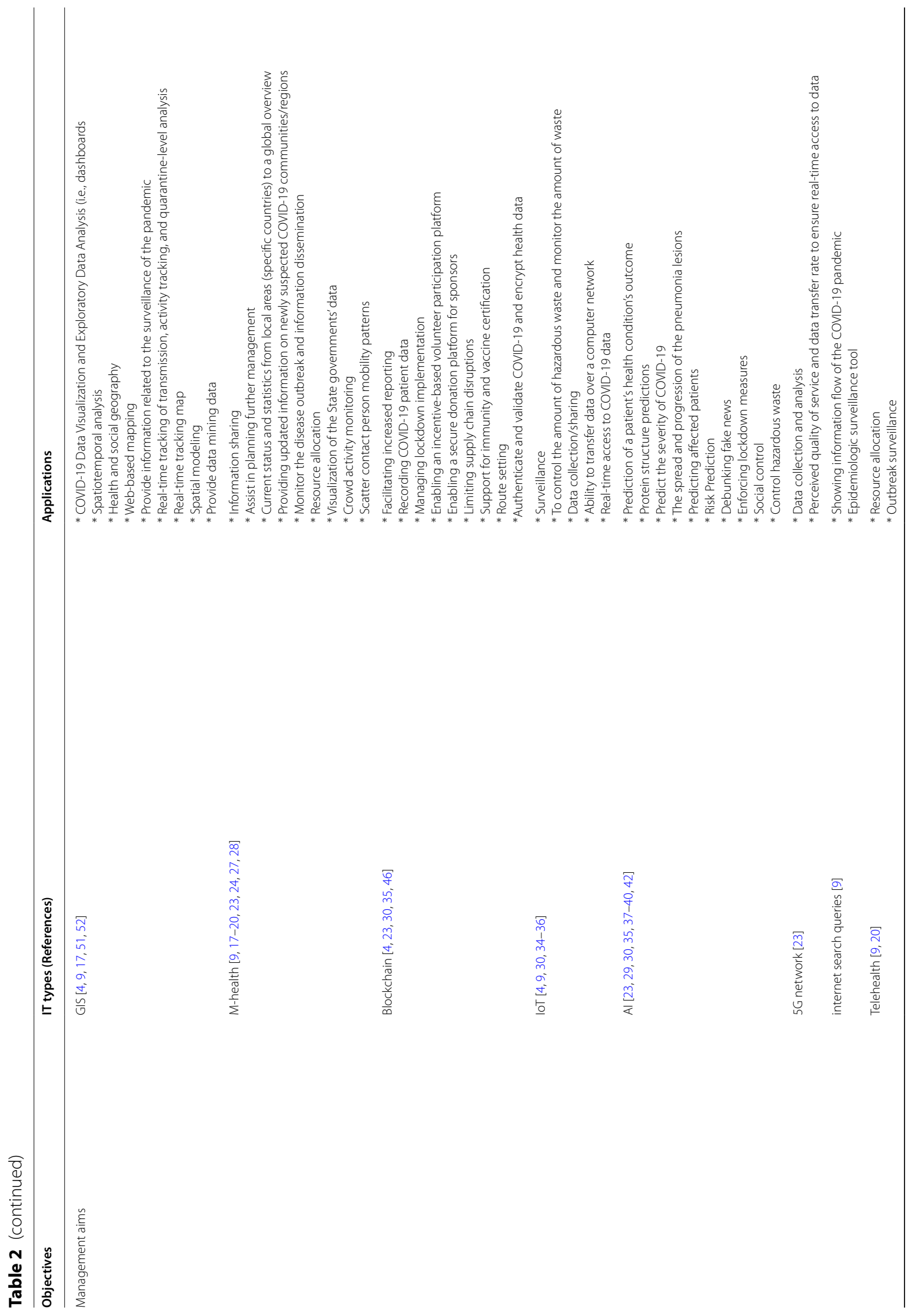




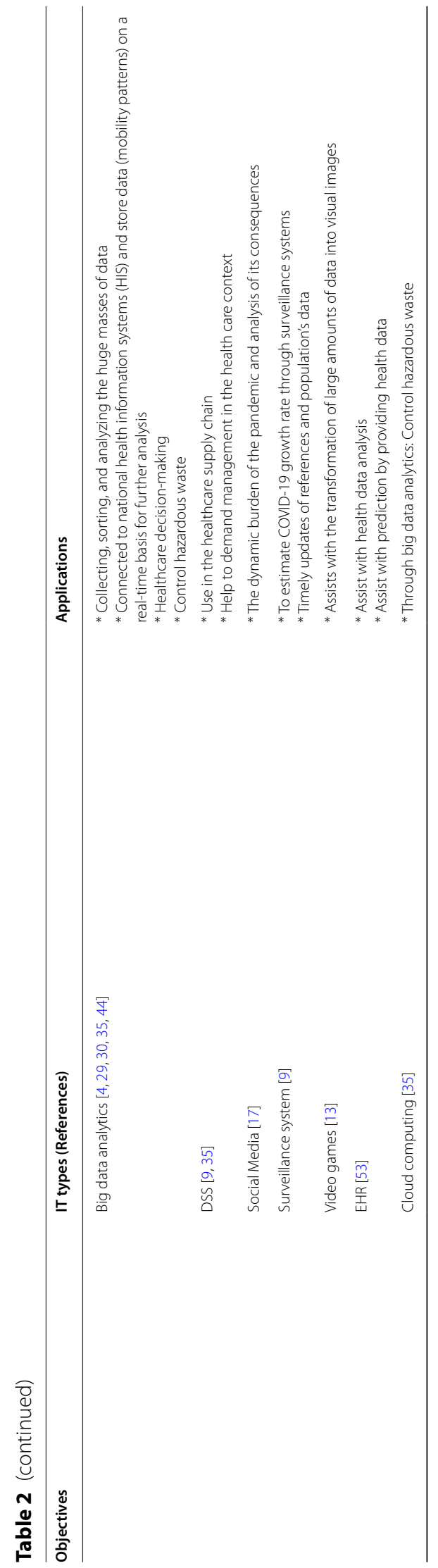




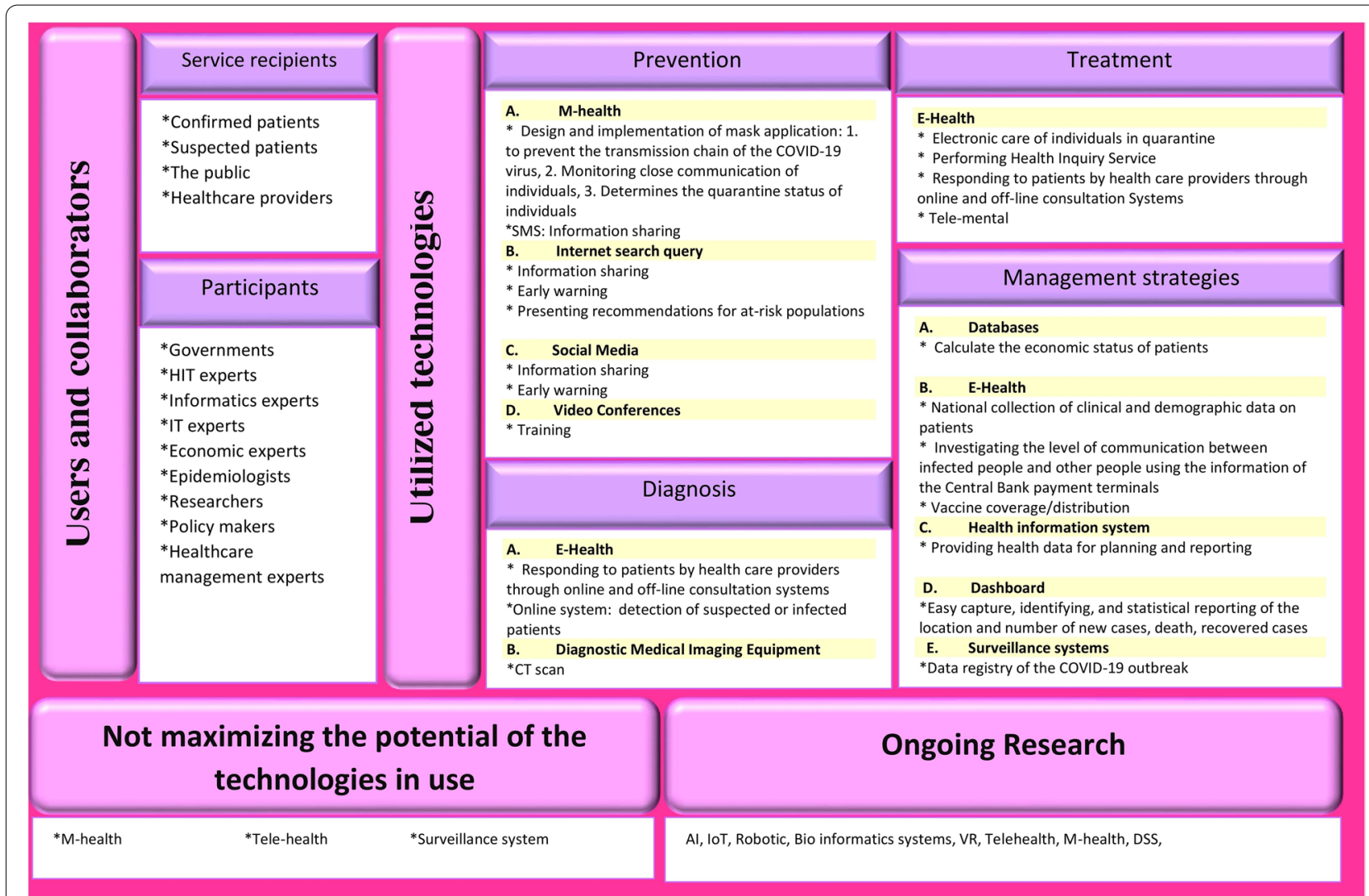

Fig. 2 A conceptual framework for managing the COVID-19 pandemic in Iran based on practical IT experience

and the infection rate in Iran's cities. Additionally, this app's purpose is to aid in the initial identification of infected or suspected cases by asking questions about an individual's physical condition [54]. WhatsApp, Telegram, Instagram, Rubika, Facebook, and Twitter have all been extensively used to share information and personal experiences about the pandemic [55]. Video conferences are another method of sharing knowledge about prevention strategies [13].

Furthermore, official websites such as those of the Ministry of Health and Medical Education and academic websites are used to educate the public about preventative measures [56, 57]. The Executive Headquarters of Imam Khomeini developed the "4030" call service in collaboration with the Ministry of Health, Treatment, and Medical Education. This E-service was developed to provide 24-hour counseling, education, and prevention, as well as to alleviate anxiety, resolve ambiguities, and dispel rumors by providing accurate and scientific responses to people's questions [58].

\section{b) Diagnosis and Detection}

Various consultation systems have been developed to assist in diagnosing infections or suspected infections
$[13,18,21,59]$. For instance, the " 4030 " call service is an appropriate digital solution for providing information on the initial diagnosis of COVID-19 via individual symptoms, thereby assisting the general public and individuals with special needs, such as pregnant women and older adults [21]. "Mashverapp" is a web-based medical and psychological counseling service that provides consultation services to patients with COVID-19. Additionally, this application provides a service for performing diagnostic tests at home [18]. "Corona's online testing program" was developed in collaboration with professors and the medical system organization. It is based on the most recent diagnostic algorithm. By asking a few medical questions and determining whether a patient requires a face-to-face visit with a physician, this program aims to reach a clinical decision $[19,20]$.

\section{iii) Treatment}

During the COVID-19 pandemic, E-health solutions based on consultation services were used to accomplish treatment objectives such as the guide to nutritional issues and the treatment of other chronic disorders [58]. As a result, the State Welfare Organization (SWO) developed an intelligent electronic system for Iranians 
to self-assess their psychological well-being during the COVID-19 outbreak. The purpose of this system is to develop appropriate content regarding an individual's mental health status, to conduct appropriate screenings based on scientific evidence, to provide expert and scientific psychological advice, and to prevent psychosocial disorders associated with the COVID-19 pandemic [24]. The National Headquarters for Coronavirus Controls' 42nd session resolution addressed the issue of "electronic care of quarantined individual". As a result, the Ministry of Communications and Information Technology (MOCIT) is required to provide the Ministry of Health and Medical Education (MOHME) with multiple electronic monitoring services for mobility management during quarantine periods [59].

\section{iv) Management and planning}

The MOHME has established a system for COVID vaccination registration. Iranians can use this system to register their national identification code, date of birth, and mobile phone number. Afterward, subscribers will be notified via SMS of the reserved vaccine time and location $[22,60]$.

Moreover, an individual's quarantine status can be determined through the "Mask" application. "The National Headquarters for Coronavirus Control" is an organization formed in early February 2020 in response to an outbreak of coronavirus in Iran. With the approval of the Supreme National Security Council, the organization has mandated that all laboratories register the National Patient Code in the integrated system of the Ministry of Health and the Ministry of Communications [59].

Additionally, the economic status of patients can be determined by combining information about infected cases announced by the Ministry of Health with data from the Iranian Welfare Database [59]. The Ministry of Communications used dashboards, surveillance systems, and the capability of telecommunication tools and mobile networks to visualize the outbreak map, identify provinces with the most incoming and outgoing passengers, determine the country's busiest locations, and calculate outbreak risk points [59].

\section{Phase 3. The proposed framework for IT-based management of COVID-19}

As illustrated in Fig. 3, a comprehensive framework for managing the COVID-19 was proposed based on extensive literature review and expert knowledge. As the framework demonstrates, 22 technologies (i.e., $\mathrm{AI}$ and its subdomains, M-health, Telehealth, VR, AR, IoT, EHR, GIS, robots, drones, blockchains, video games, five networks, DSS, surveillance system, dashboards, 3D printing, nanotechnology, bioinformatics system, Internet search query, big data analytics, and cloud computing) can be used to combat the COVID-19 outbreak. By providing a variety of services, such as virtual education and training, information sharing/awareness-raising, early warning, debunking fake news, controlling the hazardous waste, monitoring/tracking, individual assessment, sanitizing, screening infected/suspected individuals, detection/diagnosis, individual protection, data collection, data analysis, data visualization, data security, transport medical supplies, resource allocation, and remote consultation, these technologies assist in the management of the COVID-19 outbreak (see Table 1 for details).

Six categories of variables were identified: prevention, diagnosis, treatment, follow-up, management and planning, and protection. Specialized technologies are highlighted for each group. For example, prevention objectives have emphasized mobile health, Internet search queries, telehealth, robots, IoT, AI, big data, VR, and social media (see Table 1; Fig. 3 for details). Finally, the experts confirmed the proposed framework $(n=13)$, and their comments were adapted.

\section{Discussion}

This study conducts a comprehensive literature review to demonstrate the capabilities of IT in managing the COVID-19 pandemic. A conceptual framework for an IT-based pandemic response is proposed based on a literature review and expert knowledge (see Figs. 2 and 3). Iran's practical experience shows that various types and capabilities of IT were not used to respond to the COVID-19 pandemic. IT applications used against the COVID-19 outbreak are classified into six core topics in our proposed framework, namely: (1) Prevention, (2) Diagnosis, (3) Treatment, (4) Follow-up, (5) Management, and (6) Protection.

Technologies highlighted for prevention purposes include M-health $[4,9,16-28]$, Internet search query, Telehealth $[9,13,17,20,22,29-33]$, robots $[9,13,16,23$, 29, 30], IoT [9, 23, 29, 30, 34-36], AI [16, 23, 29, 30, 35, $37-43]$, big data analytics $[4,29,30,35,42,44]$, and social media $[13,17,21,29]$. M-health, internet search queries, and social media have all been used in Iran during the current pandemic. According to a study, VR, robotics, infection control systems, and AI methods should be considered more heavily during prevention [9]. Additionally, their findings indicated that prior to the COVID-19 pandemic, there were no pre-crisis efforts directed at COVID-19 prevention. Strategic planning is required to maximize the capabilities of Iran's IT $\mathrm{n}$ order to contain the outbreak's spread.

Various technologies have been considered to aid in the diagnosis of COVID-19, the most prominent of which are M-health [9, 16-22, 24, 27, 28, 31, 47], Telehealth [9, 17, 


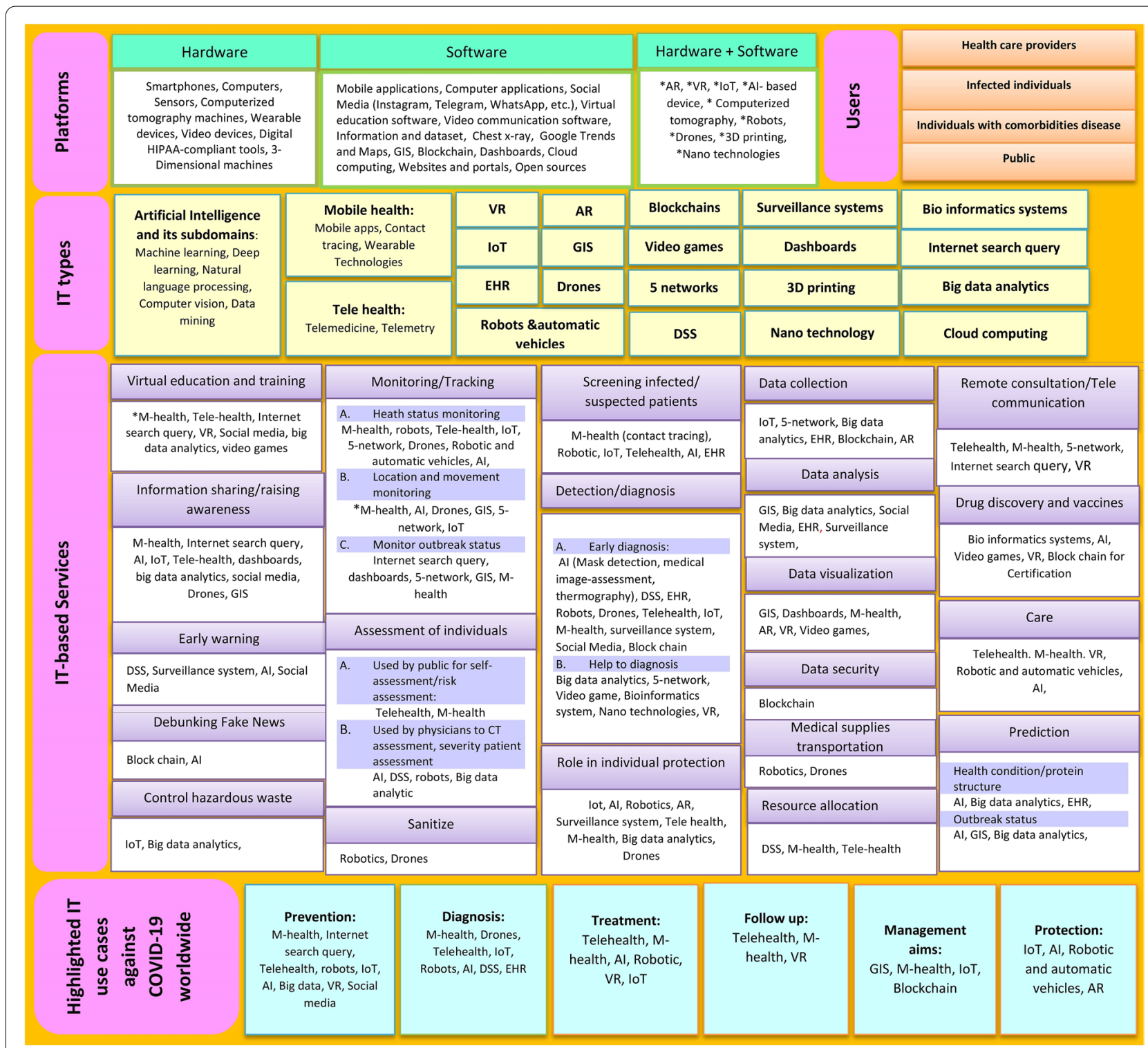

Fig. 3 Proposed Conceptual Framework based on practical experiences of IT for the management of the COVID-19 epidemic

$20,22,30,31,33]$, AI [23, 29, 30, 37-40, 42, 43, 48-50], drones [29], IoT [4, 9, 23, 30, 34, 36], and robots [9, 16, 29]. According to a study, AI, web-based genome detectives, Telehealth, M-health, IoT, surveillance systems, robotics, and DSS were all used to diagnose and detect COVID-19 patients until July 2020 [9]. Ye et al. (2020) reported that AI-based scenarios, such as drones, intelligent diagnosis (e.g., deep learning-based computer-aided diagnostic system), temperature detection (e.g., airport infrared thermal cameras), and robots (e.g., decontamination, medication delivery, and vital sign assessment), were critical in the detection and diagnosis of COVID19 in China [14]. In Iran, E-Health is used to diagnose infected individuals or those suspected of being infected, while a chest CT scan is used to diagnose COVID-9. However, many potentials of IT have not been utilized for diagnostic purposes in this country; consequently, additional opportunities for using IT for diagnostic purposes are required in this country. For instance, AI should be used to determine the severity of COVID-19 (see Fig. 3).

By providing various services, IT has aided in treating COVID-19 disease. We understand that effective treatment is contingent upon the discovery of COVID inhibitors. As a result, the use of information technologies such as AI [29, 37, 40], and VR [45] have a facilitating role in vaccine discovery. Other technologies, 
including M-health [9, 16-24, 27, 31], and telemedicine $[9,13,20,22,30-33]$, are also effective approaches in treating patients at home. Additionally, big data analytics [44], 5G networks [23], and video games [13] can be used to advance treatment goals by facilitating healthcare decision-making, teleconsultation, and drug discovery. In Iran, only a few E-health capabilities (e.g., electronic care for people in quarantine, performing health inquiry services, responding to patients via online and off-line consultation systems, and Telemental) have been used to accomplish treatment objectives during this period. Other technologies should be used to treat and monitor patients in this country (see Fig. 3).

During the COVID-19 pandemic, IT applications for management and planning were highlighted. Various technologies, such as GIS [4, 9, 17, 51, 52], M-health [9, $17-20,23,24,27,28]$, blockchain $[4,23,30,35,46]$, and IoT $[4,9,29,30,34-36]$ have been used for a variety of purposes, including control, monitoring, and tracking, information sharing, data visualization, and enabling a secure donation platform. Moreover, the use of DSS [9, $35]$, big data analytics [4, 29, 30, 35, 44], surveillance system [9], 5G network [23], Internet search query [9], video games [13], and EHR [53] are examples of additional digital solutions that can aid in decision making, data analysis, prediction, and resource allocation. Management and control of pandemic status are impossible without using IT capabilities. In other words, information technology can aid governments and decision-makers in decision-making and pandemic management by providing real-time data, facilitating information sharing, data analysis, and knowledge about valuable tools for pandemic control.

In Iran, the benefits of IT for managing and controlling the COVID-19 outbreak have been prioritized over other objectives. Consequently, decision-makers may benefit from using databases, dashboards, surveillance systems, E-health, and HIS to manage the COVID-19 disease. It is worth noting that one of Iran's primary challenges is the proliferation of databases and information resources, which has resulted in a dearth of accurate information. As a result, it is necessary to integrate this data using data mining techniques and $\mathrm{AI}$ to create valid databases. Furthermore, the use of IT to control the costs of consumables and medications should be considered. Moreover, centralized and online control of hospital beds is required to increase hospital productivity. Subsequently, our proposed framework calls for the adoption of additional digital solutions in this country.

IT has also aided in the achievement of protection goals; for example, the use of drones [23] and robots [9, $16,23,29]$ reduced the workload of healthcare workers and minimized human interaction; similarly, other technologies such as AI [23, 29, 35, 37-40, 42], and IoT $[4,9,23,34-36]$ has the potential to significantly reduce healthcare workers' workloads and facilitate the implementation of public health interventions. Additionally, by utilizing AR, patients' data can be sent directly to the healthcare system without any contact or paperwork in triage. Moreover, E-health [9, 20, 22, 31, 33] [17, 18, 24, $25,27,28]$ is another digital solution that can help minimize human interaction, particularly during the quarantine period. In Iran, the absence of protective measures is more pronounced. As a result, more attention should be paid to the use of assistive technologies to protect individuals against COVID-19 disease.

\section{Conclusions}

IT has a critical role to play in the COVID-19 outbreak. In Iran, information technology has focused on four primary categories: (1) prevention through the use of some M-health capabilities, internet search queries, and social media; (2) initial diagnosis through the use of E-health capabilities and diagnostic medical imaging equipment; (3) treatment through the use of E-health capabilities; and (4) management objectives through the use of databases, E-health, dashboards, surveillance systems, and HIS use cases. According to our proposed framework, multiple digital solutions (i.e., AI and its subdomains, M-health, Tele-health, VR, AR, IoT, EHR, Robots, drones, Blockchains, and video games, among others) should be used in a variety of fields, including prevention and detection, diagnosis, treatment, follow-up, and management, as well as the protection objectives during the COVID-19 outbreak. It should be noted that IT applications are an unavoidable component of COVID-19 management.

To summarize, various IT applications such as AI, IoT, VR, AR, DSS, blockchain, robots, drones, and video games have been ignored in Iran, as has the full potential of utilized technologies, including E-health and surveillance systems. As a result, to respond to this pandemic, Iran's government and decision-makers should consider strategic planning that incorporates successful experiences against COVID-19 and the most advanced IT capabilities.

\section{Acknowledgements \\ Not applicable.}

\section{Authors' contributions}

AA: Conceptualization, Verification, Investigation, Data Collection, Analysis and interpretation of data, Visualization, Writing - Original Draft, Review \& Editing, Supervision. ZM: Conceptualization, Verification, Investigation, Data Collection, Analysis and interpretation of data, Visualization, Writing - Original Draft, Review \& Editing, Supervision. ZF: Data Collection, Verification, Review \& Editing. SJM: Data Collection, Verification, Review \& Editing. PRH: Conceptualization, Verification, Investigation, Data Collection, Analysis and interpretation of data, Visualization, Writing - Original Draft, Review \& Editing, Supervision, Project administration. The author(s) read and approved the final manuscript. 


\section{Funding}

This research did not receive any specific grant from funding agencies in the public, commercial, or not-for-profit sectors.

\section{Availability of data and material}

The data that supported the findings of this study are available from the corresponding author on request.

\section{Declarations}

\section{Ethics approval and consent to participate}

Not applicable.

\section{Consent for publication}

Not applicable.

\section{Competing of interests}

The authors declare that there are no competing interests.

\section{Author details}

${ }^{1}$ Student Research Committee, Tabriz University of Medical Sciences, Tabriz, Iran. ${ }^{2}$ Health Information Technology Department, School of Management and Medical Informatics, Tabriz University of Medical Sciences, Daneshgah St, 5165665811 Tabriz, Iran.

Received: 3 August 2021 Accepted: 16 February 2022

Published online: 26 February 2022

\section{References}

1. Moore JH, Barnett I, Boland MR, Chen Y, Demiris G, Gonzalez-Hernandez $\mathrm{G}$, et al. Ideas for how informaticians can get involved with COVID19 research. BioData mining. 2020;13:3. doi:https://doi.org/10.1186/ s13040-020-00213-y

2. Kolifarhood G, Aghaali M, Mozafar Saadati H, Taherpour N, Rahimi S, Izadi $\mathrm{N}$, et al. Epidemiological and Clinical Aspects of COVID-19; a Narrative Review. Arch Acad Emerg Med. 2020;8(1):e41-e.

3. Baj J, Karakuła-Juchnowicz H, Teresiński G, Buszewicz G, Ciesielka M, Sitarz E, et al. COVID-19: specific and non-specific clinical manifestations and symptoms: the current state of knowledge. Journal of clinical medicine. 2020;9(6):1753.

4. Mbunge E. Integrating emerging technologies into COVID-19 contact tracing: Opportunities, challenges and pitfalls. Diabetes \& metabolic syndrome. 2020;14(6):1631-6. doi:https://doi.org/10.1016/j.dsx.2020.08. 029

5. dashboard W. [Available from: https://www.worldometers.info/coron avirus/.

6. Doosti-Irani A, Haghdoost AA, Najafi F, Eybpoosh S, Moradi G, Bagheri Amiri F, et al. How Can the Epidemic Curve of COVID-19 in Iran Be Interpreted? J Res Health Sci. 2020;20(3):e00491-e. doi:https://doi.org/10. 34172/jrhs.2020.27

7. Raoofi A, Takian A, Sari AA, Olyaeemanesh A, Haghighi H, Aarabi M. COVID-19 pandemic and comparative health policy learning in Iran. Archives of Iranian medicine. 2020;23(4):220-34.

8. Papadopoulos T, Baltas KN, Balta ME. The use of digital technologies by small and medium enterprises during COVID-19: Implications for theory and practice. Int J Inf Manage. 2020;55:102192. https://doi.org/10.1016/j. ijinfomgt.2020.102192.

9. Asadzadeh A, Pakkhoo S, Saeidabad MM, Khezri H, Ferdousi R. Information technology in emergency management of COVID-19 outbreak. Informatics in medicine unlocked. 2020;21:100475. doi:https://doi.org/10. 1016/j.imu.2020.100475

10. Malden S, Heeney C, Bates DW, Sheikh A. Utilizing health information technology in the treatment and management of patients during the COVID-19 pandemic: lessons from international case study sites. Journa of the American Medical Informatics Association: JAMIA. 2021. https:// doi.org/10.1093/jamia/ocab057.

11. Mohsenzadeh F, Isfandyari-Moghaddam A. Application of information technologies in academic libraries. Electron Library. 2009;27(6):986-98.
12. Cozzarin BP. Impact of organizational innovation on product and process innovation. Economics of Innovation and New Technology. 2017;26(5):405-17.

13. Sarbadhikari S, Sarbadhikari SN. The global experience of digital health interventions in COVID-19 management. Indian journal of public health. 2020;64(Supplement):S117-s24. doi:https://doi.org/10.4103/ijph.IJPH_ 457_20

14. Ye Q, Zhou J, Wu H. Using Information Technology to Manage the COVID-19 Pandemic: Development of a Technical Framework Based on Practical Experience in China. JMIR medical informatics. 2020;8(6):e19515. doi:https://doi.org/10.2196/19515

15. Haleem A, Javaid M. Medical 4.0 and its role in healthcare during COVID19 pandemic: A review. J Ind Integration Manag. 2020;5(4):1-19.

16. Vargo D, Zhu L, Benwell B, Yan Z. Digital technology use during COVID-19 pandemic: A rapid review. Human Behavior and Emerging Technologies. 2021;3(1):13-24. doi:https://doi.org/10.1002/hbe2.242

17. Niakan Kalhori SR, Bahaadinbeigy K, Deldar K, Gholamzadeh M, HajesmaeelGohari S, Ayyoubzadeh SM. Digital health solutions to control the COVID-19 pandemic in countries with high disease prevalence: Literature review. J Med Internet Res. 2021;23(3):e19473. https://doi.org/10.2196/19473.

18. Kondylakis H, Katehakis DG, Kouroubali A, Logothetidis F, Triantafyllidis A, Kalamaras I, et al. COVID-19 Mobile apps: A systematic review of the literature. J Med Internet Res. 2020;22(12):e23170. https://doi.org/10. 2196/23170.

19. Islam MN, Islam I, Munim KM, Islam AKMN. A Review on the Mobile Applications Developed for COVID-19: An Exploratory Analysis. IEEE Access 2020;8:145601-10. doi:https://doi.org/10.1109/ACCESS.2020.3015102

20. Eslami P, Kalhori SRN, Taheriyan M. eHealth solutions to fight against COVID-19: A scoping review of applications. Medical Journal of the Islamic Republic of Iran. 2021;35(1):1-14. doi:https://doi.org/10.34171/ mijiri.35.43

21. Dixit S, Nandakumar G. Promoting healthy lifestyles using information technology during the COVID-19 pandemic. Reviews in cardiovascular medicine. 2021;22(1):115-25. doi:https://doi.org/10.31083/j.rcm.2021.01. 187

22. Ding X, Clifton D, Ji N, Lovell NH, Bonato P, Chen W, et al. Wearable Sensing and Telehealth Technology with Potential Applications in the Coronavirus Pandemic. IEEE Reviews in Biomedical Engineering. 2021;14:48-70. doi:https://doi.org/10.1109/RBME.2020.2992838

23. Chamola V, Hassija V, Gupta V, Guizani M. A Comprehensive Review of the COVID-19 Pandemic and the Role of loT, Drones, Al, Blockchain, and 5G in Managing its Impact. IEEE Access. 2020;8:90225-65. doi:https://doi.org/ 10.1109/ACCESS.2020.2992341

24. Psychological self-assessment system in the coronavirus crisis. Available from: http://corona.behzisti.ir/.

25. Asadzadeh A, Kalankesh LR. A scope of mobile health solutions in COVID-19 pandemics. Informatics in medicine unlocked. 2021;23:100558. doi:https://doi.org/10.1016/j.imu.2021.100558

26. Iyengar K, Upadhyaya GK, Vaishya R, Jain V. COVID-19 and applications of smartphone technology in the current pandemic. Diabetes and Metabolic Syndrome: Clinical Research and Reviews. 2020;14(5):733-7. doi:https://doi.org/10.1016/j.dsx.2020.05.033

27. Almalki M, Giannicchi A. Health Apps for Combating COVID-19: Descriptive Review and Taxonomy. JMIR mHealth and uHealth. 2021;9(3):e24322. doi:https://doi.org/10.2196/24322

28. Adans-Dester CP, Bamberg S, Bertacchi FP, Caulfield B, Chappie K, Demarchi D, et al. Can mHealth Technology Help Mitigate the Effects of the COVID-19 Pandemic? IEEE Open Journal of Engineering in Medicine and Biology. 2020;1:243-8. doi:https://doi.org/10.1109/OJEMB.2020. 3015141

29. Islam MN, Islam AKMN. A Systematic Review of the Digital Interventions for Fighting COVID-19: The Bangladesh Perspective. IEEE Access 2020;8:114078-87. doi:https://doi.org/10.1109/ACCESS.2020.3002445

30. Haleem A, Javaid M. Medical 4.0 and its role in healthcare during covid-19 pandemic: A review. Journal of Industrial Integration and Management. 2020;5(4):531-45. doi:https://doi.org/10.1142/S2424862220300045

31. Bokolo Anthony J. Use of Telemedicine and Virtual Care for Remote Treatment in Response to COVID-19 Pandemic. Journal of medical systems. 2020;44(7):132. doi:https://doi.org/10.1007/s10916-020-01596-5

32. Bahl S, Singh RP, Javaid M, Khan IH, Vaishya R, Suman R. Telemedicine technologies for confronting covid-19 pandemic: A review. Journal of 
Industrial Integration and Management. 2020;5(4):547-61. doi:https://doi. org/10.1142/S2424862220300057

33. Anthony Jnr B. Implications of telehealth and digital care solutions during COVID-19 pandemic: a qualitative literature review. Informatics for health \& social care. 2021;46(1):68-83. doi:https://doi.org/10.1080/17538157. 2020.1839467

34. Swayamsiddha S, Mohanty C. Application of cognitive Internet of Medical Things for COVID-19 pandemic. Diabetes and Metabolic Syndrome: Clinical Research and Reviews. 2020;14(5):911-5. doi:https://doi.org/10.1016/j. dsx.2020.06.014

35. Rahayu P, Rohajawati S, Fairus S, Saragih H, Akbar H, editors. Challenges and Recommendation of the Information Technologies Application in Hazardous Medical Waste Management amidst Pandemic Covid-19. J Phys. 2021;1844:012029. https://doi.org/10.1088/1742-6596/1844/1/ 012029.

36. Ndiaye M, Oyewobi SS, Abu-Mahfouz AM, Hancke GP, Kurien AM, Djouani K. IOT in the Wake of COVID-19: A Survey on Contributions, Challenges and Evolution. IEEE Access. 2020;8:186821-39. doi:https://doi.org/10. 1109/ACCESS.2020.3030090

37. Vaishya $R$, Javaid $M$, Khan IH, Haleem A. Artificial Intelligence (Al) applications for COVID-19 pandemic. Diabetes \& metabolic syndrome. 2020;14(4):337-9. doi:https://doi.org/10.1016/j.dsx.2020.04.012

38. Senthilraja M. Application of Artificial Intelligence to Address Issues Related to the COVID-19 Virus. SLAS technology. 2021;26(2):123-6. doi:https://doi.org/10.1177/2472630320983813

39. Latif S, Usman M, Manzoor S, lqbal W, Qadir J, Tyson G, et al. Leveraging Data Science to Combat COVID-19: A Comprehensive Review. IEEE Transactions on Artificial Intelligence. 2020;1(1):85-103. doi:https://doi.org/10. 1109/TAl.2020.3020521

40. Kumar A, Gupta PK, Srivastava A. A review of modern technologies for tackling COVID-19 pandemic. Diabetes \& metabolic syndrome. 2020;14(4):569-73. doi:https://doi.org/10.1016/j.dsx.2020.05.008

41. Ulhaq A, Born J, Khan A, Gomes DPS, Chakraborty S, Paul M. COVID19 Control by Computer Vision Approaches: A Survey. IEEE Access. 2020;8:179437-56. doi:https://doi.org/10.1109/ACCESS.2020.3027685

42. Bragazzi NL, Dai H, Damiani G, Behzadifar M, Martini M, Wu J. How Big Data and Artificial Intelligence Can Help Better Manage the COVID-19 Pandemic. Int J Environ Res Public Health. 2020;17(9):3176. https://doi. org/10.3390/ijerph17093176.

43. Ikram T, Saeed A, Ayn N, Tahir MA, Mumtaz R, editors. A review of the prevalent ICT techniques used for COVID-19 SOP violation detection. HONET 2020 - IEEE 17th International Conference on Smart Communities: Improving Quality of Life using ICT, IoT and Al; 2020. p. 19498. https://doi.org/10.1109/HONET50430.2020.9322821.

44. Alsunaidi SJ, Almuhaideb AM, Ibrahim NM, Shaikh FS, Alqudaihi KS, Alhaidari FA, et al. Applications of Big Data Analytics to Control COVID-19 Pandemic. Sensors (Basel, Switzerland). 2021;21(7):2282.

45. Asadzadeh A, Samad-Soltani T, Rezaei-Hachesu P. Applications of virtual and augmented reality in infectious disease epidemics with a focus on the COVID-19 outbreak. Informatics in medicine unlocked. 2021;24:100579. doi:https://doi.org/10.1016/j.imu.2021.100579

46. Ricci L, Maesa DDF, Favenza A, Ferro E. Blockchains for COVID-19 Contact Tracing and Vaccine Support: A Systematic Review. IEEE Access. 2021;9:37936-50. doi:https://doi.org/10.1109/ACCESS.2021.3063152

47. Sadighbayan D, Ghafar-Zadeh E. Portable Sensing Devices for Detection of COVID-19: A Review. IEEE Sensors Journal. 2021;21 (9):10219-30. doi:https://doi.org/10.1109/JSEN.2021.3059970

48. Ito R, Iwano S, Naganawa S. A review on the use of artificial intelligence for medical imaging of the lungs of patients with coronavirus disease 2019. Diagnostic and interventional radiology (Ankara, Turkey). 2020;26(5):443-8. https://doi.org/10.5152/dir.2019.20294.

49. Ozsahin I, Sekeroglu B, Musa MS, Mustapha MT, Uzun Ozsahin D. Review on Diagnosis of COVID-19 from Chest CT Images Using Artificial Intelligence. Computational and mathematical methods in medicine. 2020;2020:9756518. https://doi.org/10.1155/2020/9756518.

50. Islam MM, Karray F, Alhajj R, Zeng J. A Review on Deep Learning Techniques for the Diagnosis of Novel Coronavirus (COVID-19). IEEE Access. 2021;9:30551-72. doi:https://doi.org/10.1109/ACCESS.2021.3058537

51. Franch-Pardo I, Napoletano BM, Rosete-Verges F, Billa L. Spatial analysis and GIS in the study of COVID-19. A review. The Science of the total environment. 2020;739:140033. doi:https://doi.org/10.1016/j.scitotenv. 2020.140033

52. Saran S, Singh P, Kumar V, Chauhan P. Review of Geospatial Technology for Infectious Disease Surveillance: Use Case on COVID-19. Journal of the Indian Society of Remote Sensing. 2020;48(8):1121-38. doi:https://doi. org/10.1007/s12524-020-01140-5

53. Mohammadzadeh Z, Maserat E, Kariminezhad R. Application of Information Technology Models, Approaches and Tools in Covid-19 Management: Rapid Review. Depiction of Health. 2021;12(1):78-95.

54. "MASK" application [Available from: https://mask.ir/.

55. Hosseini P, Hosseini P, Broniatowski DA. Content analysis of Persian/Farsi Tweets during COVID-19 pandemic in Iran using NLP. arXiv preprint arXiv:200508400. 2020.

56. Ministry of Health and Medical Education [Available from: https://behdasht.gov.ir/\%D8\%A7\%D8\%AE\%D8\%A8\%D8\% A7\%D8\%B1-\%DA\%A9\%D8\%B1\%D9\%88\%D9\%86\%D8\%A7\%D9\%88\%DB\%8 C\%D8\%B1\%D9\%88\%D8\%B3.

57. Tabriz University of Medical Sciences [Available from: https:/eazphcp. tbzmed.ac.ir/Page/3120/\%DA\%A9\%D8\%B1\%D9\%88\%D9\%86\%D8\%A7\% 20\%D9\%88\%DB\%8 C\%D8\%B1\%D9\%88\%D8\%B3.html.

58. A review of 40 actions of the Welfare Organization of the country (Iran). Social Security Research institute; 2020. Available from: https://www. behzisti.ir/d/2020/04/14/0/50459.pdf.

59. Center for Presidential Strategic Studies. Evaluate Iran's experiences in using the capacities of new information and communication technologies in Corona management 2020 [Available from: https://media.coron omy.ir/uploads/org/2020/12/29/160923844163005000.pdf.

60. Maserat E, Keikha L, Davoodi S, Mohammadzadeh Z. E-health roadmap for COVID-19 vaccine coverage in Iran. BMC public health. 2021;21 (1):1450. doi:https://doi.org/10.1186/s12889-021-11419-y

\section{Publisher's Note}

Springer Nature remains neutral with regard to jurisdictional claims in published maps and institutional affiliations.

Ready to submit your research? Choose BMC and benefit from:

- fast, convenient online submission

- thorough peer review by experienced researchers in your field

- rapid publication on acceptance

- support for research data, including large and complex data types

- gold Open Access which fosters wider collaboration and increased citations

- maximum visibility for your research: over $100 \mathrm{M}$ website views per year

At BMC, research is always in progress.

Learn more biomedcentral.com/submissions 